\title{
Matrix models for algal life history stages
}

\author{
P.O. Ang, Jr, R.E. De Wreede \\ Department of Botany, University of British Columbia, Vancouver, British Columbia, Canada V6T 2B1
}

\begin{abstract}
Matrix models based on size and stage, corresponding to the monophasic, biphasic and triphasic life histories of algae have been constructed. Similarities and differences of these models with the Leslie matrix model, as well as with other extensions and modifications of it, are discussed. Two examples are given to show the utility of these models: one based on field data for Sargassum siliquosum J. Ag. and a second, based on data for Laminaria longicruris Pyle, taken from the literature. Stable size distribution, reproductive values, sensitivity and elasticity of these models are analyzed. Many algae show discrete episodes of growth, reproduction, die back and regeneration. Hence, discrete matrix models appear to realistically describe the life history processes of these algae.
\end{abstract}

\section{INTRODUCTION}

A discrete projection model for population dynamics was first proposed for use on animal populations grouped in age classes (Lewis 1942, Leslie 1945, 1948). Various extensions of this model have made it applicable to organisms grouped in growth stages (e.g. Lefkovitch 1965) or in sizes (e.g. Usher 1966). Plant population biologists have found models based on size more appropriate for their use since, in many cases, plant size is more closely correlated to demographic events than is plant age (Harper 1977, see review by Caswell 1986). Hughes (1984) also proposed that colonial organisms such as corals are better grouped by size than by age. Several models have now been proposed for trees grouped in growth sizes (Hartshorn 1975, Enright \& Ogden 1979), annuals grouped by age and size (Law 1983), and biennials grouped by age or size (Werner \& Caswell 1977), or grouped by size and sex (Meagher 1982).

For algae, many studies have emphasized aspects of biomass production. Demographic events, e.g. survival, mortality, recruitment and fecundity of individual plants and of the population, have received far less attention. Several studies have shown that some large algae (e.g. kelps) can be aged by using growth rings found in the stipe (e.g. Frye 1918, Kain 1963, De Wreede 1984, Klinger \& De Wreede 1988), but there has been no other known way to reliably age algae, except by following a cohort through time. Following cohorts of algae is difficult and has many technical problems, such as recognizing the same individuals over time. The complex life histories characteristic of many algae, their isomorphic or heteromorphic stages and their possession of monoecious or dioecious thalli, make demographic analysis even more intractable.

Three basic algal life history patterns, namely monophasic, diphasic and triphasic life histories, are commonly recognized. In the monophasic life history, only a haploid gametophytic stage or a diploid sporophytic stage is present. The diphasic life history is characterized by alternation of gametophytic and sporophytic stages, with either stage being physically dominant or both stages being co-dominant. The triphasic life history is typical of many red algae where a third stage, a carposporophytic stage, forms on the gametophytic blade. The female gametophyte with the attached carposporophytic stage is referred to in this paper as a cystocarpic plant (or stage). Apogamy and apospory are found among some species. Recent reviews have noted many variations in these 3 types of life history among members of the 3 major groups of macrobenthic algae, the Chlorophyta (Tanner 1981), Phaeophyta (Pederson 1981), and Rhodophyta (West \& Hommersand 1981).

That size may be a better descriptor of demographic events than age has not been demonstrated for algae. Chapman (1986) showed that for the sporophytic stage of Laminaria longicruris Pyle., size was not related to mortality but was clearly related to reproduction. Age was only partially related to mortality, but was unrelated to reproduction. Fecundity data for many algae are based on the number of reproductive structures per 
unit area of the reproductive thallus, and hence are related to thallus size (Kain 1975, De Wreede 1986). Further studies are necessary to establish the importance of size. But given the modular character of many algae, it is likely that algal demographic events are best described based on size.

Fig. 1 shows the different stages of a diphasic life history based on size, and considers most of the possible variations that could occur. While these variations may not all be found in a single species, the complexity of some algal life histories is obvious. Some of these stages are rare, or are microscopic and transient, and are unlikely to be traceable in the field, making a complete demographic study of algae difficult. Some stages may be more important than the others, e.g. while apogamy or apospory may occur, they probably do so in only a small fraction of the population and their effect on the different demographic events may thus be a minor one. Fig. 2 shows what we believe to be the dominant pathways in the 3 life history patterns. Some of these stages may not be measurable directly, but a close approximation can be made based on relevant criteria. As long as these limitations are kept in mind, and necessary adjustments made to account for them, demographic analysis using only these dominant stages can yield meaningful information about the population.
We present here 3 matrix models that describe these 3 basic types of algal life history based on size and stage. Using field data for 2 species of brown algae, namely Sargassum siliquosum J. Ag, and Laminaria longicruris, we demonstrate the utility of two of these models in exploring the relative importance of the different life history stages or size classes to the population growth of each of these species. We have not been able to find sufficient information in the literature on the demography of red algae to allow us to illustrate the utility of the third model.

\section{THE MODELS}

The basic projection matrix model is given as

$$
\mathbf{n}_{t+1}=\mathbf{A} \mathbf{n}_{t}
$$

In the case of a Leslie matrix, $\mathbf{n}_{t}$ is a column vector whose elements represent the number of individuals in each age class at time $t, \mathbf{n}_{t+1}$ represents number of individuals in each age class at time $t+1$, and $\mathbf{A}$ is the transition matrix describing the change in the population from $t$ to $t+1$. Where the state variable is size and/ or stage, $\mathbf{n}_{t}$ and $\mathbf{n}_{t+1}$ represent vectors whose elements are numbers of individuals in each size class, or in each size class of each stage, at the respective time

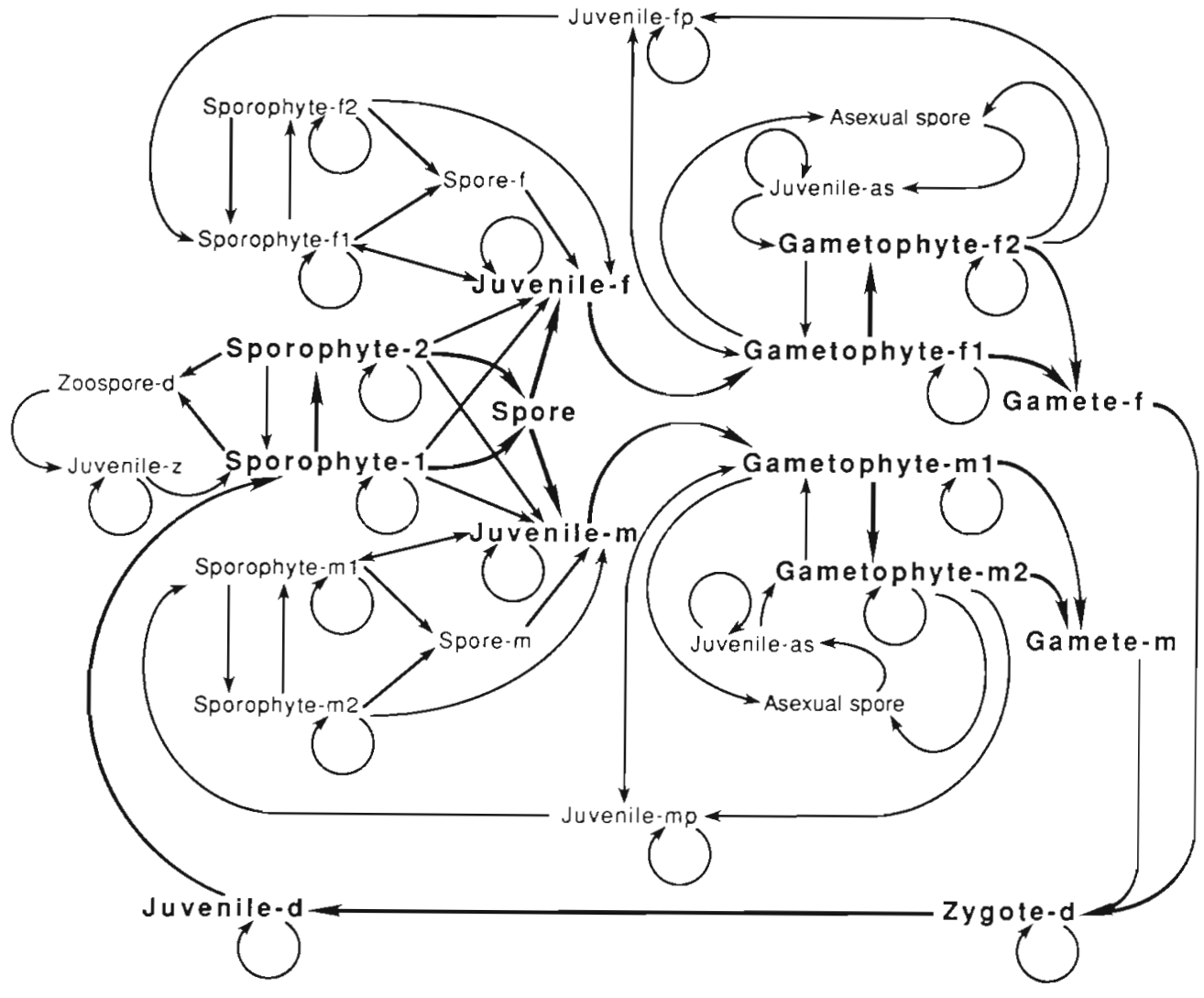

Fig. 1. Flow diagram of a diphasic algal life history showing most of the possible transitions from stage to stage, or within the different size classes. Numbers denote size class number, as: asexual d: diploid; f: female; fp: female parthenogenetic $\mathrm{m}$ : male; mp: male parthenogenetic; p: parthenogenetic; z: zoosporic 
Plants of different sizes may have different rates of growth. It is possible for some individuals to grow through more than one size class within a given period of time. Algae are also subject to erosion from waves, herbivory, or, as a periodic phenomenon, some species die back after the reproductive period. Hence, it is also possible for them to return to a smaller size class (cf. Hughes 1984 for corals). Thus, the transition matrix A that describes these phenomena needs not have the non-zero values confined only to the elements in the first row and the principal subdiagonal, as in the Leslie matrix. Because many algae go through different phenological phases within a year, it would be appropriate to generate transition matrices that correspond to these phenological events. The time interval covered by these matrices would then depend on the duration

A

B
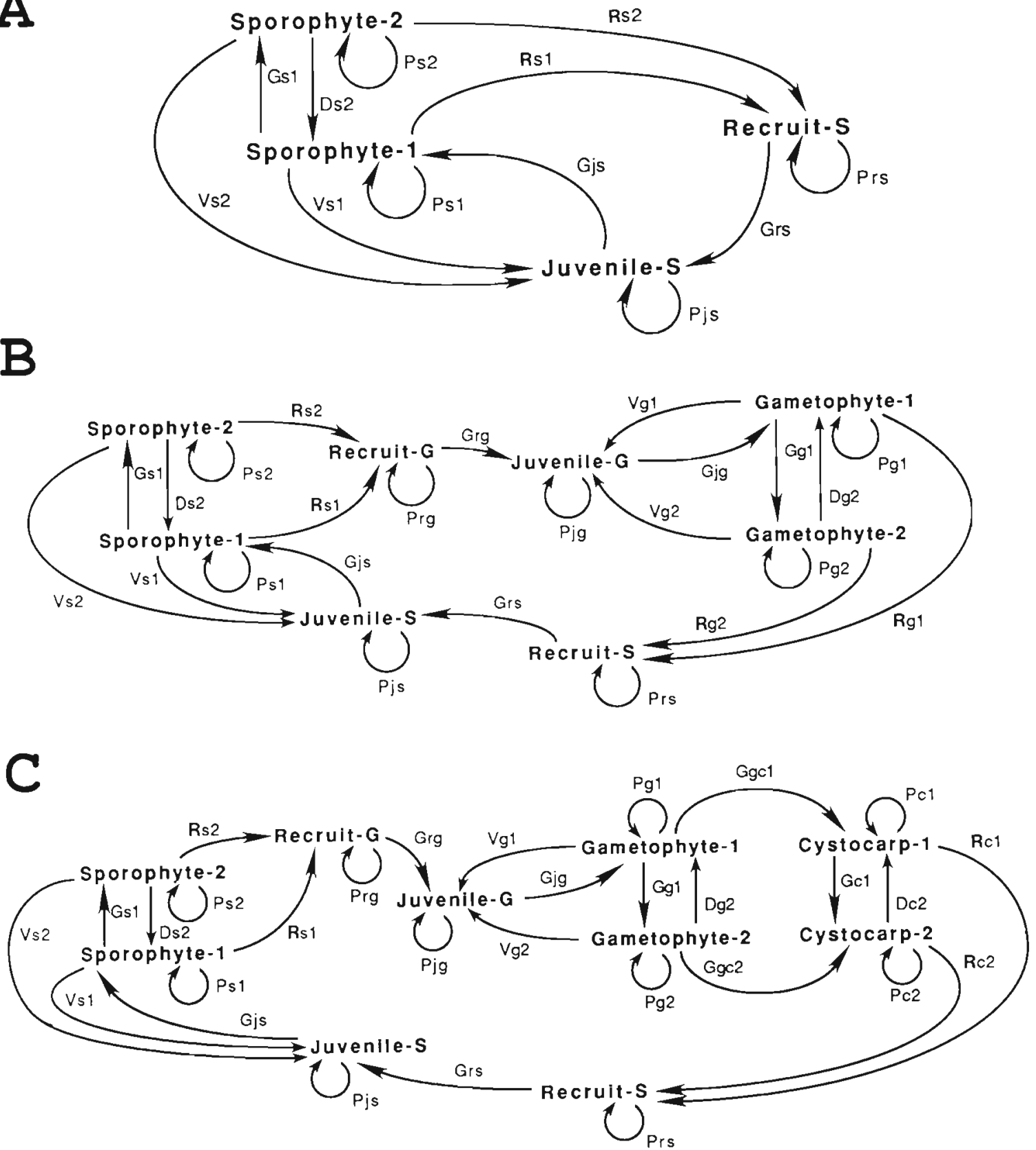

Fig. 2. Simplified flow diagram of (A) monophasic life history with sporophyte as the only dominant stage, (B) diphasic life history and (C) triphasic life history. In (B) and (C), only the female gametophytes are shown. D: degeneration; R: recruitment; $G$ : growth; P: probability of staying in same stage or size class; $V$ : vegetative regeneration; $c$ : cystocarpic, g: gametophytic; j: juvenile; $r$ recruit; s: sporophytic: numbers: size class number 
of these events. It is likely that any algal population would first be sampled at regular intervals, e.g. biweekly or monthly for a year, before its phenology could be established. Thus, transition matrices could be generated with a transition time interval equal to that of the sampling interval. In both cases, the product of the matrices, whether based on phenological or sampling events, would then describe a projection interval equivalent to $1 \mathrm{yr}$.

Algae also exhibit sexuality. However, because males do not really contribute to population growth, for simplicity, only females are considered in the following models. In a dioecious sporophytic or gametophytic population, fecundity or recruitment rates would have to be adjusted based on the ratio between male and female, e.g. these values must be halved if male to female ratio is 1 . Males could still be included, and their inclusion would constitute an extension of these models.

\section{Monophasic model}

For a monophasic life history, the transition matrix is analogous to the one proposed by Hughes (1984). In a matrix for algae with only the diploid sporophytic stage, the $\mathrm{R}$ terms in the first row represent recruitment rate (Table $1 \mathrm{~A}$ ). Recruits are usually the products of sexual reproduction and, less frequently, those of asexually produced spores. Recruitment rate is therefore a measure of fecundity and of the survival probability of zygotes or spores becoming recruits. The probability that a plant will stay in the same size class within a unit of time is given by the P terms. The term $G$ describes the probability of moving from one size class to a larger size class (i.e. growth) and $D$, that of moving to a smaller size class (i.e. degeneration). The P, G, and D terms have values ranging from 0 to 1 . The term $V$ describes the probability of die back and subsequent regeneration from the holdfast. This resembles vegetative reproduction (sensu Sarukhàn \& Gadgil 1974), especially if more than one plant axis is regenerated from the holdfast that eventually leads to the formation of more than one individual. Regenerating holdfasts are grouped with juveniles because in general, they are larger and have a higher probability of survival than the recruits. The transition matrix for algae with a dioecious sporophytic stage or a haploid gametophytic stage is analogous to that described above when only female plants are considered.

\section{Diphasic model}

The matrix model for a diphasic life history (Table $1 B$ ) is analogous to the one presented by Law (1983).
But instead of age and size, the model consists of stage and size, where stage refers to either the sporophytic or gametophytic stage. The transition matrix can be reduced to its submatrices given as:

$$
\left[\begin{array}{ll}
A & D \\
C & B
\end{array}\right]
$$

where $\mathbf{A}$ and $\mathbf{B}$ are transition matrices of the sporophytic and gametophytic stages respectively, and $\mathbf{C}$ and $\mathbf{D}$ describe the transition from one stage to the other. The transition elements within $\mathbf{A}$ and $\mathbf{B}$ are similar to those in the monophasic model. These submatrices can be analyzed separately and need not be of the same size. In many algae, either sporophyte or gametophyte may be microscopic; in such cases, the microscopic stage would be placed in a single size class. The model may then be reduced to one analogous in form to the monophasic model.

\section{Triphasic model}

In the triphasic algal life history 3 stages are involved, the sporophytic (or tetrasporophytic), gametophytic, and the cystocarpic stages (Table $1 \mathrm{C}$ ). This triphasic model can also be reduced to its component submatrices:

$$
\left[\begin{array}{lll}
A & 0 & F \\
D & B & 0 \\
0 & E & C
\end{array}\right]
$$

where $\mathbf{A}, \mathbf{B}$ and $\mathbf{C}$ are the transition matrices of the 3 stages; $\mathbf{D}, \mathbf{E}$ and $\mathbf{F}$ are the transition matrices between stages. Where no transition is possible, e.g. from sporophytic stage to cystocarpic stage, the matrix is a zero matrix.

The triphasic model is an expansion of the diphasic model. However, apart from the presence of an additional stage, the cystocarpic stage, the transition from a gametophytic to a cystocarpic stage does not have to pass through a juvenile stage. A female gametophyte becomes cystocarpic after successful fertilization and the growth of the attached carposporophytic stage. Hence, a female gametophyte belonging to a certain size class will transform to become a cystocarpic stage of the same size class, except when there is growth or erosion of its thallus. Contributions of cystocarpic plants to sporophytic recruits are indicated by $R_{c 1}$ and $R_{c 2}$ in Table $1 C$.

\section{Sensitivity and elasticity analyses}

To be biologically meaningful, all the models presented above are non-negative. In some plant and 
many animal populations, there are individuals that eventually cease to contribute to future generations. Algae do not exhibit such a phenomenon. In all the 3 life histories, there exists a pathway by which each size class or stage can contribute sexually or vegetatively to individuals of another size class or stage. Thus, matrices describing algal populations are irreducible. Furthermore, the presence of at least one positive diagonal element in the matrices, representing the possibility of an individual remaining in a size class or stage, means that the matrices are also primitive. This implies the existence of a real dominant eigenvalue $\left(\lambda_{m}\right)$ with positive right (w) and left (v) eigenvectors (Caswell 1986). The population will thus converge on a stable size distribution described by $\mathbf{w}$ and growing at a rate equivalent to $\lambda_{\mathrm{m}}$. The left eigenvector $\mathrm{v}$ describes the reproductive value of the different size classes, i.e. the contribution of each size class to future generations (Leslie 1948, Caswell 1986).

Various authors have tested the sensitivity of their matrix models numerically by evaluating the effect of varying proportionally the matrix entries on the intrinsic rate of increase (e.g. Usher 1966). This process, however, could be tedious especially where a large matrix is involved. Caswell (1978) derived a general formula for the sensitivity analysis of $\lambda_{m}$ to changes in the entries of the projection matrix that can be readily applied to the algal models. This sensitivity measures the absolute change in $\lambda_{\mathrm{m}}$ caused by a small change in the matrix entries. It is also possible to calculate the elasticity, or the proportional change in $\lambda_{\mathrm{m}}$ caused by a change in the matrix entries (Caswell 1986). These elasticities have the additional advantage of measuring the relative contribution of the matrix entries to $\lambda_{\mathrm{m}}$ (Caswell 1986).

\section{EXAMPLES}

Most demographic studies of algae reported in the literature do not lend themselves to matrix analysis. Two examples are given to demonstrate the utility of the monophasic and diphasic models. In both examples, missing parameters have been estimated based on some fundamental assumptions about the life histories of these algae. In each case, these assumptions are given and the way the parameters are estimated is briefly described. Because these missing parameters have had to be estimated, these examples should not be taken as representing the absolute dynamics of the 2 populations modelled.

Example 1: Sargassum is a brown alga with a monophasic life history. Plants are sporophytic (sensu Jensen 1974) and may be monoecious or dioecious, annual or

Table 1. Matrix models of algae with (A) monophasic, $(B)$ diphasic, and (C) triphasic life history, and their corresponding column vector. Symbols follow those used in Fig. 2 and correspond to the transition elements in the respective life cycle graph.

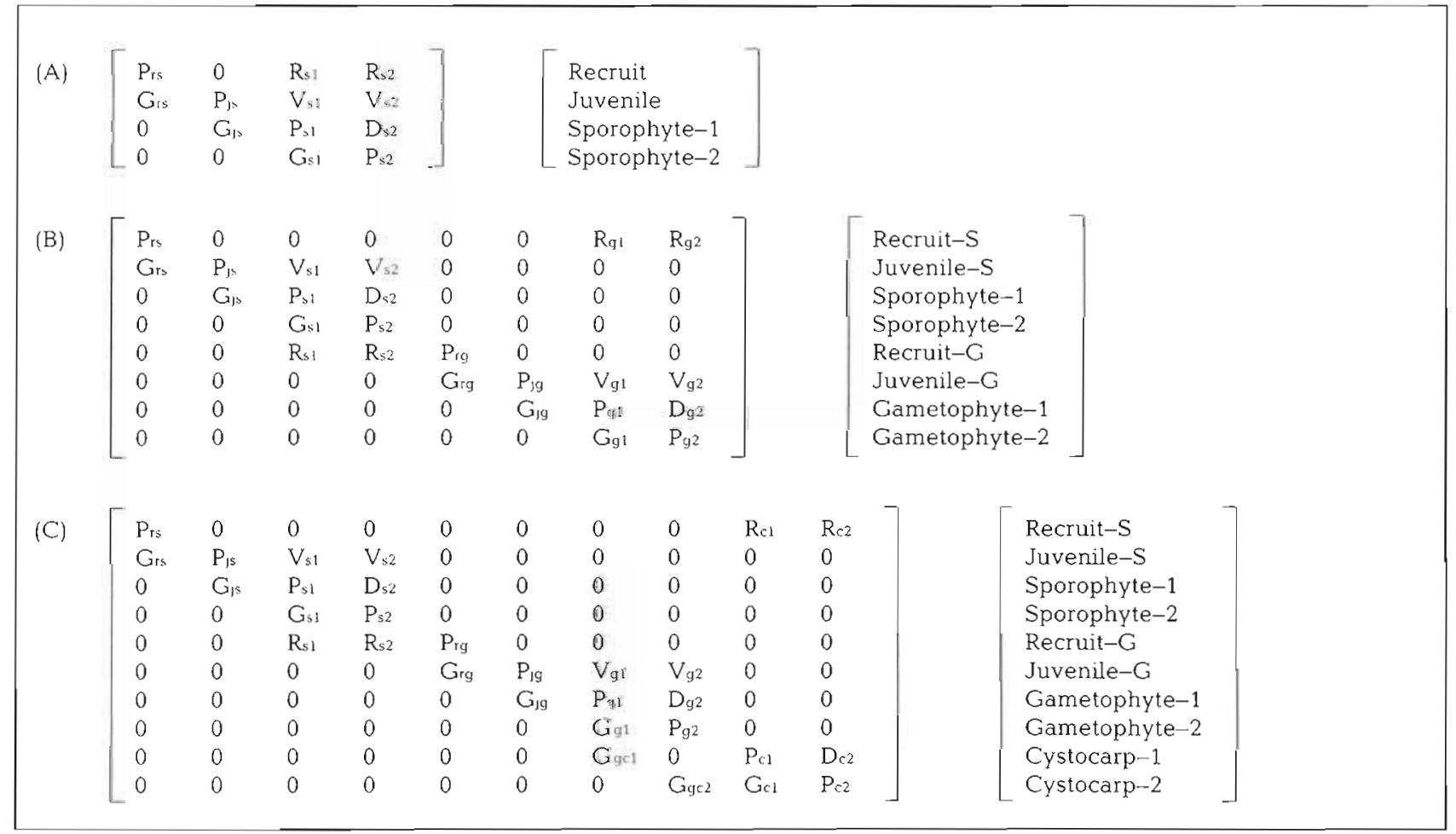


perennial. Ang (1985a) showed the growth pattern of Sargassum siliquosum J. Ag. to be characterized by a regenerative and slow growth phase, a fast growth phase, a reproductive phase and a die-back and recruiting phase. This species is monoecious and pseudoperennial, i.e. only the holdfast, not the whole plant, persists through several years. Data used in this example were collected from Balibago, Calatagan, Philippines (Ang unpubl.). Plants in four $1 \mathrm{~m}^{2}$ quadrats were measured every second month from December 1979 to November 1980. In each case, the quadrats were haphazardly selected. We were not able to follow the same plants over the observation period. For the purpose of this exercise, we assume that even if we did, the population structure obtained would not be significantly different from what was obtained based on haphazardly selected quadrats. Each time, the population sampled was divided into 7 classes: recruits, Size Class 1 of juveniles and regenerating holdfasts of not more than $20 \mathrm{~cm}$ in length, and 5 other size classes each with size intervals of $20 \mathrm{~cm}$. Based on information obtained from selected tagged plants used in growth studies (Ang 1985a), we estimated that $60 \%$ of the surviving individuals remained in the same size class, and $40 \%$ moved to the next higher size class between each sampling interval during the period of slow growth. All surviving individuals moved at least one size class higher during the period of fast growth. Growth among larger plants declined during the reproductive period, so that only individuals in Size Classes 1 and 2 experienced growth. All of the plants except those in Size Class 1 experienced die-back during the die-back period. Hence, those that survived eventually ended up in Size Class 1 with the juveniles.

The number of eggs produced per plant during the reproductive period was not measured, nor was the mortality rate between the eggs and recruits. Only the actual number of recruits per $0.25 \mathrm{~m}^{2}$ was measured (Ang 1985b). We assume that the number of recruits produced per $0.25 \mathrm{~m}^{2}$ is proportional to the volume of the plant, which then is allometrically related to its length. Recruitment values were thus estimated as the average number of recruits produced per plant of each size class as a function of plant length, i.e. the longer the plant, the larger its volume, the more recruits it produces.

Six matrices were constructed, each covering a time interval of 2 mo. The first 2 matrices correspond to the regeneration and slow growth phase, the second 2 to the fast growth phase, and the last 2 to the reproductive phase and the die-back and recruiting phases respectively. Each matrix gives the resulting population structure that conforms to that observed in the field at that particular time interval. The product of these 6 matrices is a matrix, $\mathrm{S}$, with all non-zero, non-negative elements (Table 2), with a period of operation equivalent to $1 \mathrm{yr}$.
Matrix analysis could be performed on each of the 6 matrices to show the dynamics of the population within each phenological phase. However, for our purpose, only the results of the analysis on Matrix $\mathbf{S}$ are presented here. This analysis shows that the rate of increase of the population is only slightly above unity $\left(\lambda_{m}=1.0264\right)$ indicating that the population is very stable. Fig. 3A shows the stable size distribution and the reproductive values of the different size classes in $\log$ scale. The proportion of the number of recruits in a stable distribution is extremely small and most of the plants (about $76 \%$ ) are in Size Classes 1 (juvenile) to 3 . This is not unusual for a size-structured population (Caswell 1986). As expected, the reproductive values of the plants vary in direct proportion to their sizes.

The sensitivity matrix, $\mathbf{S}_{\mathrm{s},}$ (Table 2 ) shows the trend for population growth rate to be more sensitive to transitional changes from smaller to larger size classes, as indicated by the increasing values of the elements from Rows 1 to 7 within each column. However, transition from recruits to larger size classes $\left(s_{s(i, 2),}, i=2\right.$ to 7$)$ appears to be unimportant. Except for this, sensitivity values tend to decrease progressively across the rows from left to right. This trend is analogous to that observed for teasel Dipsacus sylvestris Huds, and was interpreted by Caswell \& Werner (1978) to indicate the importance of early reproduction and faster developmental rates on the overall growth rate of the population. In the case of Sargassum, early reproduction would refer to vegetative reproduction, i.e. regeneration from holdfasts. The insignificant contribution to the population growth rate by recruits, compared to the contribution of each of the other size classes, is further shown in the elasticity matrix $\mathbf{E}_{\mathrm{s}}$ (Table 2), where the production of recruits $\left(e_{s(1, j)}, j=2\right.$ to 7$)$ and their transitions to larger size classes $\left(e_{5(i .1)}, i=2\right.$ to 7$)$ are all close to zero.

The results of the sensitivity and elasticity analyses appear to reflect the population dynamics of Sargassum reasonably well. The damping ratio, which is the ratio between the largest and the next largest eigenvalues, is very much larger than 1 , suggesting that a stable size distribution was attained very rapidly and in the present example, within 1 operation of the matrix (= 1 yr cycle). Because the plants die back every year, 'new' plants arise not only from recruits but also from regeneration of the holdfasts. The latter appears to be more important than the former. This is readily observed in the field. New recruits are infrequently observed except during the first 2 or 3 mo immediately after reproduction (Ang 1985b). Although recruits may appear in large numbers in those few months, on an annual basis changes in their numbers do not seem to have a significant effect on the overall population growth rate. 
Table 2. Sargassum siliquosum. Projection matrix $\mathbf{S}$ for a population with a monophasic life history, and its corresponding sensitivity matrix $\mathbf{S}_{\mathrm{s}}$ and elasticity matrix $\mathbf{E}_{\mathrm{s}}$. The column vector $\mathbf{S}_{N}$ shows the arrangement of the size classes

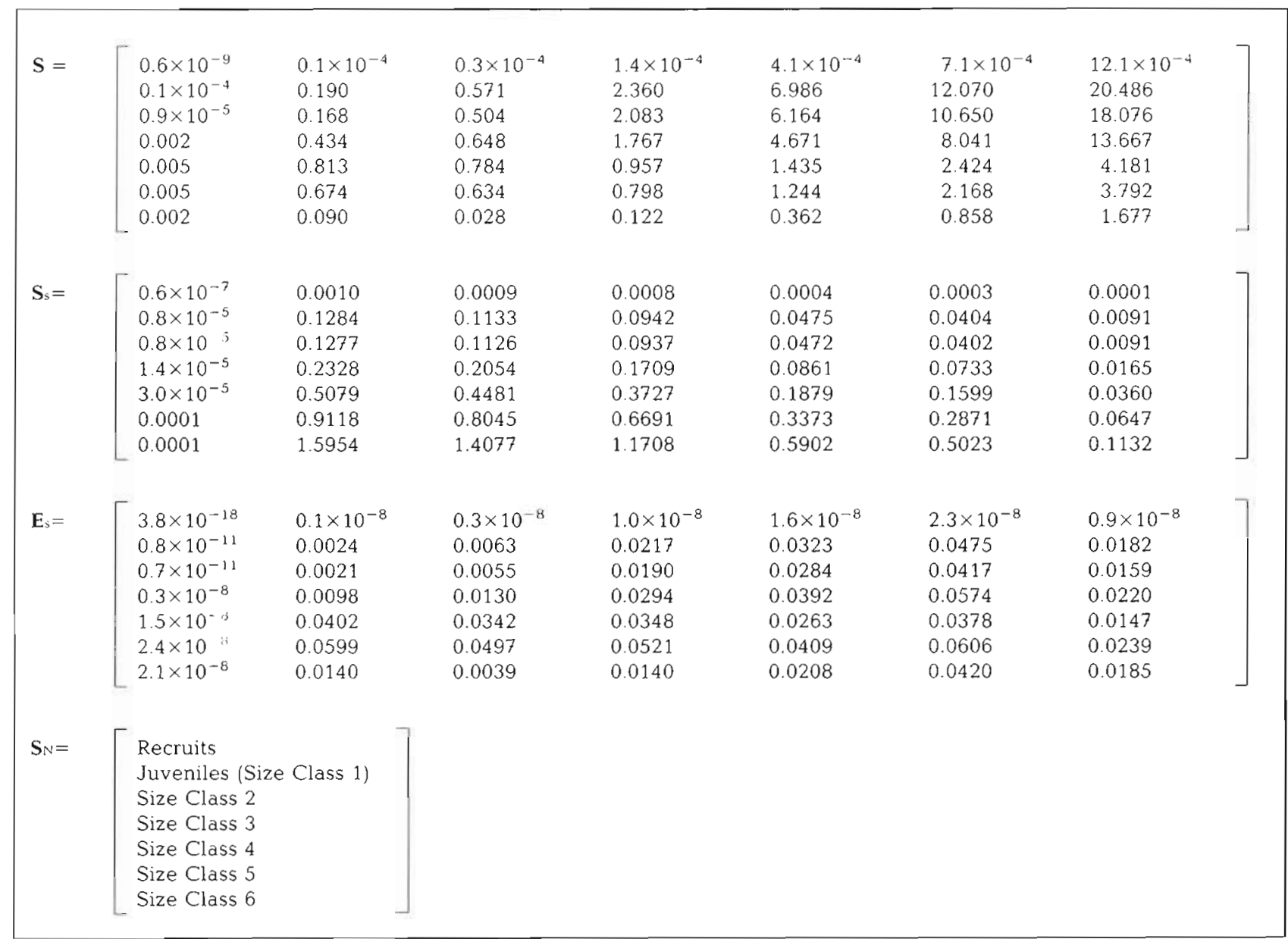

A. SARGASSUM SILIQUOSUM

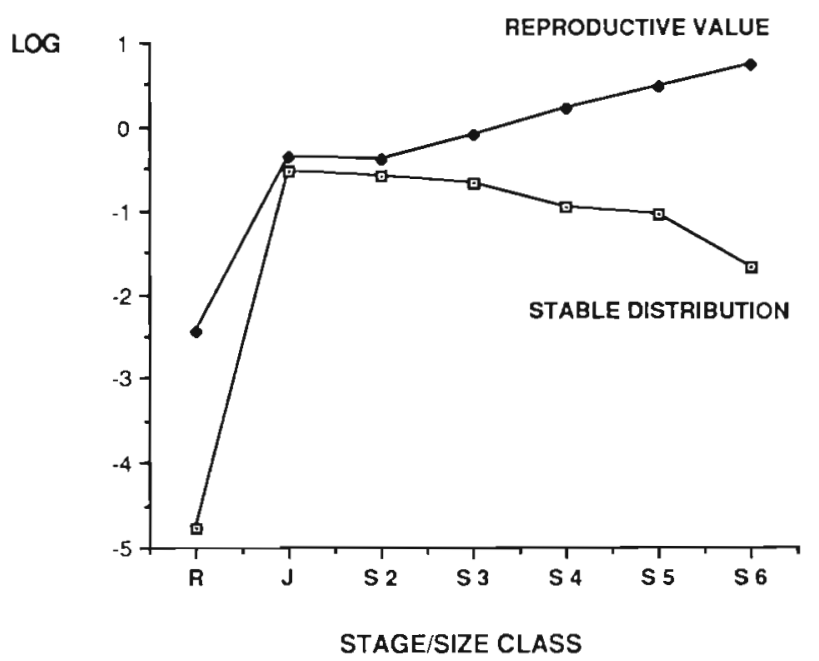

B. LAMINARIA LONGICRURIS

LOG

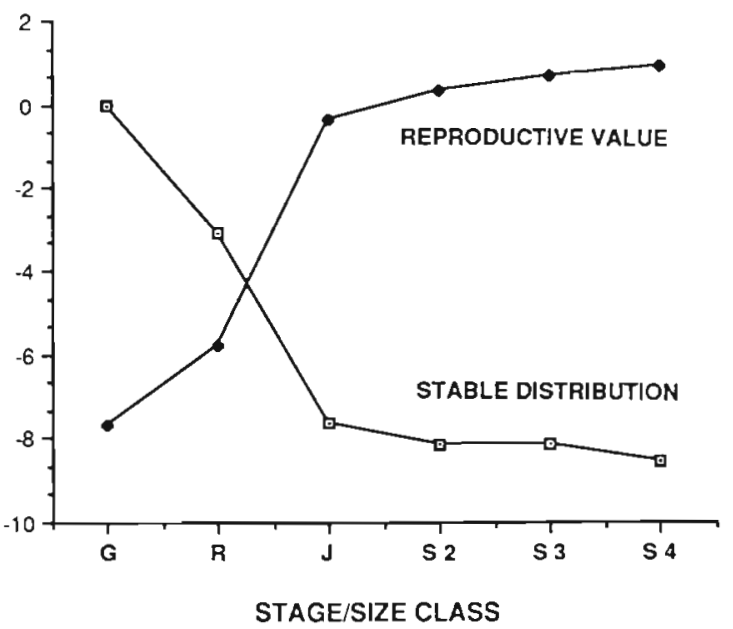

Fig. 3. (A) Sargassum siliquosum and (B) Laminaria longicruris. Stable size distribution and reproductive values as a function of the stage/size classes. G: gametophyte; R: recruits; J: juvenile (Size Class 1); S number: size class number 
Example 2: Laminaria is another common brown alga of north temperate seas. Its life history is characterized by an alternation of macroscopic sporophytic and microscopic free-living gametophytic stages. Reproduction is seasonal and normally occurs after a period of rapid growth. Reproductive structures are known as sori, and are formed on both sides of the blades producing billions of spores per season (Kain 1963, Klinger 1984). In some species, reproductive blades eventually become eroded and new growth starts again from the basal part of the blade (Kain 1963, 1976, 1977). Spores give rise to male and female gametophytes in equal ratio (Schreiber 1930 cited in Chapman 1984). Each female gametophyte is believed to produce one egg which, when fertilized, gives rise to a new sporophyte (Lüning 1980). Gametophytes can persist over long periods, and can grow vegetatively and become fragmented, giving rise to new clonal gametophytes (Hsiao \& Druehl 1973). Chapman (1984, 1986) made a detailed study of spore production, recruitment, and survival rates of sporophytic plants of Laminaria longicruris in eastern Canada. The matrix that we constructed is primarily based on data from that research. Other information on the gametophytic stage, sex ratio, sporophytic population structure and growth of this eastern Canadian population are incomplete. Some assumptions have to be made regarding them and these assumptions are based on data from other populations of Laminaria.

For our purposes, the gametophytic stage, being microscopic, is grouped in only one size class. The sporophytic stage can be divided into the smallest size class of recruits, juveniles of not more than $100 \mathrm{~cm}$ in length, and 3 other larger size classes in $100 \mathrm{~cm}$ length intervals. We assume that the sporophytic population has a bimodal distribution, i.e. there are more individuals in smaller and larger size classes than in the middle size class as was observed in Laminaria populations around the Isle of Man, the west mainland of Scotland and the southern outer Hebrides (all British Isles; Kain 1977). We further assume that members of the middle size class tend to grow faster when the canopy opens up as a result of higher mortality of larger plants in fall and winter. Six matrices are constructed to correspond to the six 2 mo periods of a year. In each matrix, we have not included the spores as a size category. Only the number of female gametophytes is considered, and we assume that it takes 2 mo for a spore to be formed, released and to become a gametophyte, and another 2 mo for an egg produced by the gametophyte to be fertilized and to become a sporophytic recruit large enough to be detected by eye in the field. This assumption is based on the observations of Klinger (1984) and Chapman (1984) on the germination of spores and the laboratory examination on the growth of new sporo- phytic recruits. The number of female gametophytes produced is assumed to be $2.5 \%$ of the number of spores produced, and is proportional to the size of the sporophytes. In other words. we assume that the spores suffer a $95 \%$ mortality and only $5 \%$ ever become gametophytes after 2 mo. Of these, half are female. Based on the observation of Chapman (1984, Tables 3 and 4), we estimated that from about $1 \%$ (August to October) to $20 \%$ (December to February) of the fertilized eggs produced from the female gametophytes eventually become sporophytic recruits. High mortality of recruits has been observed by Chapman (1984) and only about $0.0001 \%$ of the recruits ever become juveniles.

The transition elements in the matrix are estimated from the cohort life table (Table 1 of Chapman 1986) and the mean length of all plants in the cohort (Fig. 2 of Chapman 1986). Laminaria longicruris appears to experience a fast growth period, a period of reproduction followed by erosion of the old blades, and a period of new growth. We calculated that plants less than 150 $\mathrm{cm}$ in length continue to grow throughout the year, and move to the next size class in about 4 mo. Larger plants suffer some erosion of their blades after reproduction, hence becoming smaller during November through January. As is the case with the Sargassum matrices, each matrix covering every 2 mo period gives a resulting population structure that conforms to that observed in the field. The product of these 6 matrices is the projection matrix $\mathbf{L}$, for the whole year (Table 3).

Based on this matrix the population is growing at a rate $\lambda_{m}=1.04$, and with a damping ratio very much greater than 1 This is consistent with the observation of Chapman (1984) that the total number of plants in the population does not appear to be changing. The greatest proportion of the plants is in the gametophytic stage and the number of plants in the larger size classes decreases rapidly (Fig. 3B). The actual number of gametophytes in the field has been difficult to ascertain but, given the number of spores produced by the sporophytes and their ability to reproduce asexually, such a high number is expected. On the other hand, the correspondingly low number of plants in the sporophyte size classes suggests a very high mortality in the transition from gametophyte to sporophytic recruits, and from recruits to juveniles. The bimodal size structure of the population is not distinct at the stable distribution. The pattern of the reproductive value is typical, where larger plants have a larger share in the contribution to future generations.

The sensitivity matrix, $\mathbf{S}_{\mathrm{L}}$, (Table 3 ) shows a similar trend to that observed in the Sargassum matrix. Sensitivity to gametophyte and recruit production appears to be extremely small. However, it should be remembered that these production values are measured on a 
different scale to all the other elements in the transition matrix. The sensitivity values for the transition from the gametophyte and the recruits to larger size classes, $\left(s_{L(1,1)}, i=3\right.$ to 6$)$ and $\left(s_{L(i, 2)}, i=3\right.$ to 6$)$ respectively, are extremely high, suggesting the great impact it would have to the population growth rate if the development of gametophytes and recruits to maturity were speeded up. The elasticity matrix, $E_{L}$, (Table 3 ) shows the relative contributions of the different size and stage classes to population growth rate in the same scale. The transition from gametophyte to recruits and to plants of larger size classes $\left(\sum_{1=2}^{6} e_{L(i, 1)}\right)$ contributes about $21 \%$ to the population growth rate, whereas the transition from recruits to plants of larger size classes $\left(\sum_{i=3}^{6} e_{L(i, 2)}\right)$ accounts for only $1 \%$. This shows the relative importance of the gametophytic stage to the dynamics of this population. With millions of gametophytes being formed from the even larger number of spores produced by the sporophytes, the number that eventually become sporophytic recruits is not critical (as indicated by $\left.e_{L(2,1)}=0.008\right)$ as long as some of them eventually reach maturity (cf. $e_{L(6.1)}=0.078$ ). On the other hand, $53 \%$ of the population growth rate is accounted for by the transitions of the plants within the last 3 size classes $\left(\sum_{j=4}^{6} \sum_{i=4}^{6} e_{L(i . j)}\right)$. This suggests that although large plants may be present in only very small number (Fig. 3B), they are more important in the maintenance of the population growth rate than the gametophytes and plants of smaller sizes.

\section{DISCUSSION}

In both the examples we have examined cases where the dominant stage is sporophytic (sensu Jensen 1974), followed by either a microscopic gametophytic stage, as in Laminaria or, in the case of Sargassum, with the gametophytic stage being absent. These are clearly among the simplest life histories in macroalgae. While it is theoretically possible to construct a more elaborate matrix to include all the possible transitional pathways depicted in Fig. 1, this would be intractable. Although inclusion of more of the transitional parameters would

Table 3. Laminaria longicruris. Projection matrix L for a population with a diphasic life history, and its corresponding sensitivity matrix $S_{L}$ and elasticity matrix EL. The column vector $L_{N}$ shows the arrangement of the stage and size classes. (Based on data from Chapman 1984, 1986)

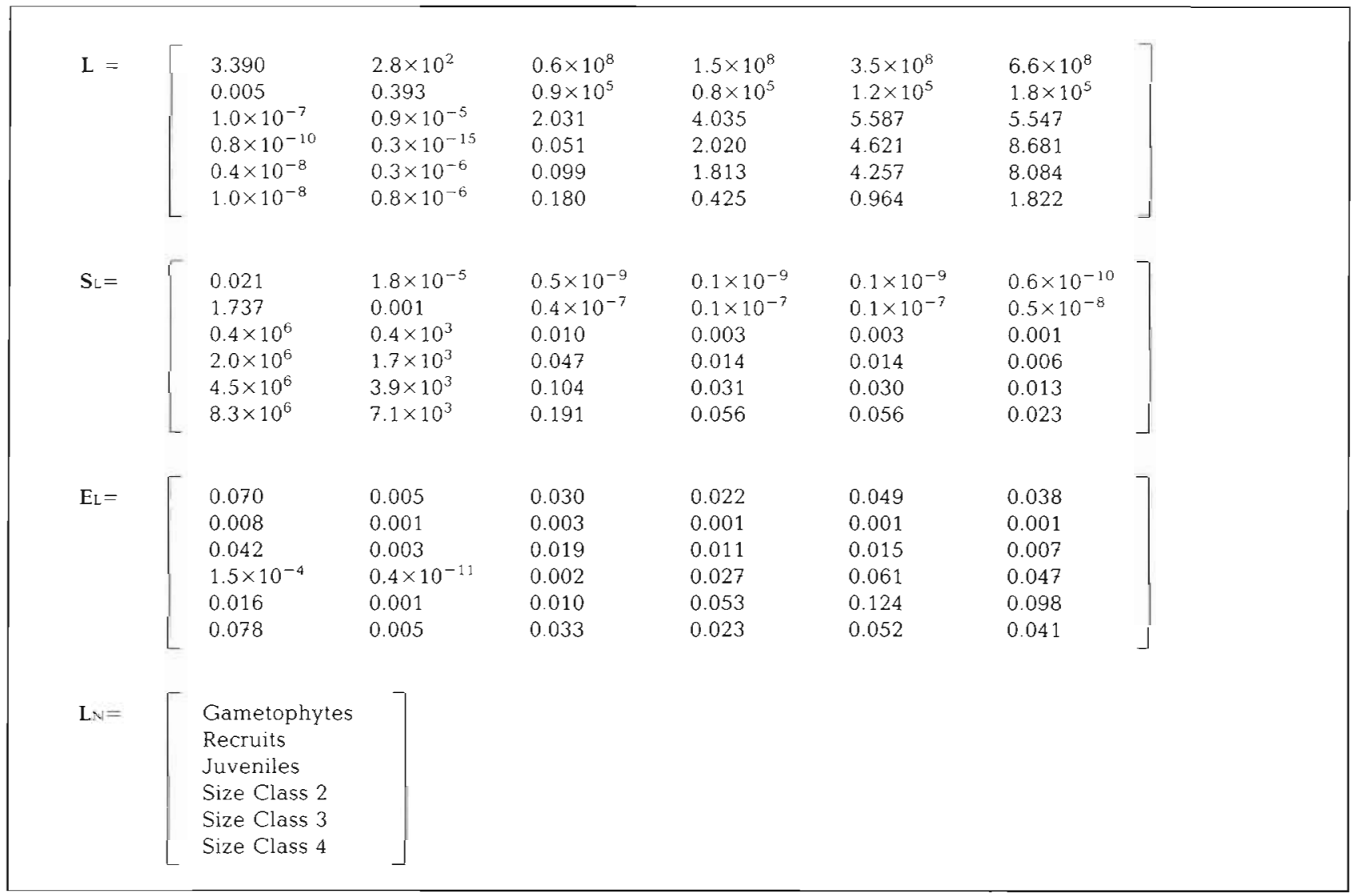


undoubtedly improve the resolution of the model, this advantage may be overshadowed by the fact that such parameters are often difficult to measure and hence are subject to greater measurement errors. Given these limitations, assumptions have to be made regarding these parameters. Sensitivity and elasticity analyses of the matrix indicate how accurately these parameters must be estimated, and how important these estimates are to the overall population growth rate. In the case of Sargassum, the recruitment rate and the survival probability of the recruits are difficult to estimate in the field. But these terms are less critical than others (e.g. survival probability of the larger plants) to the population growth rate, as indicated by their near-zero values in both the sensitivity matrix $\mathbf{S}_{\mathrm{s}}$ and the elasticity matrix $\mathbf{E}_{\mathrm{s}}$ (Table 2). Reasonably accurate analysis of the population would thus be possible as the other parameters of greater importance can all be estimated with greater confidence in the field. Because the production of Laminaria gametophytes and their survival and vegetative growth are relatively important to the population growth rate but are difficult to estimate in the field, there will always be a limit to the accuracy with which the dynamics of a Laminaria population can be analyzed. Any assumptions or estimates relating to gametophytes must therefore be made with care. Given that the other parameters can be estimated more accurately, manipulation of the parameters related to gametophytes can be used to provide additional information on their effects on the population.

Many algae exhibit discrete episodes of growth, reproduction, die back and regeneration. Discrete models like matrix models may thus be an appropriate tool for studying such algal populations. The time interval through which a matrix operates depends on the biological phenomena associated with the population being modelled. There is usually strong seasonality among algae, therefore, a projection model operating within a shorter time interval may be able to describe such populations more accurately. Woodward (1982) pointed out that a limitation of the Leslie model and its modified form put forward by Usher (1966) is that the models assume the fecundity and transition probability terms (and by extension, all the other terms in our models) to apply equally to all individuals within the respective age or size class within each operation of the matrix. Woodward proposed that this limitation could be overcome by considering the age distribution among individuals within an age or size class. For most algae, however, determination of age is extremely difficult. Furthermore, since size is probably a better descriptor of algal demographic events than age, the inclusion of age distribution may not add much information to what can already be derived by knowing the size distribution. Nevertheless, the probability distribu- tion of a transition event and the distribution within a size class should be of interest in future investigations.

An algal gametophyte can produce more gametophytes, and/or at the same time contributes to sporophyte production. Such a case resembles Life History Case C in Caswell (1982, 1986), where there would be fecundity terms (or, in our case, recruitment terms) among stages. As pointed out by Klinger (1984). such complexity in the algal life history is not the same as the complexity exhibited by higher plants with their seed bank (Schmidt \& Lawlor 1983). Seeds in the seed bank do not produce more seeds.

Most population models consider only females in their analysis. However, where the sex ratio or the interaction between the 2 sexes is known, the models of Meagher (1982) may be adapted, since these models can show the importance of the contribution of each sex to the population structure and growth. Other extensions of the Leslie matrix model, including those incorporating density effects (e.g. Solbrig et al. 1988) and stochastic events (e.g. Pollard 1966), are worth considering with respect to algal population dynamics. Our models represent only a small contribution towards this end.

Acknowledgements. This study was partially funded by Natural Science and Engineering Research Council of Canada grant no. 5-89872 to R. De Wreede. We thank C. Lai, M. Pascual-Dunlap and $M$. Weis for help with the computer programme and graphics. Critical comments from G. Bradfield, H. Caswell, P. G. Harrison, T. Klinger, R. Turkington and 3 anonymous reviewers greatly improved earlier drafts of the manuscript. P.O. Ang held an UBC graduate fellowship and an ICOD fellowship during the early part of this study.

\section{LITERATURE CITED}

Ang, P. Jr. O. (1985a). Phenology of Sargassum siliquosum J. Ag. and S. paniculatum J. Ag. (Sargassaceae, Phaeophyta) in the reef flat of Balibago, Calatagan. Philippines. Proc. 5th Int. Coral Reef Symp. 5: 51-57

Ang, P. Jr. O. (1985b). Studies on the recruitment of Sargassum spp. (Sargassaceae, Phaeophyta) in Balibago, Calatagan, Philippines. J, exp. mar Biol. Ecol. 91: 293-301

Caswell. H. (1978). A general formula for the sensitivity of population growth rate to changes in life history parameters. Theor Population Biol. 14:215-230

Caswell, H. (1982). Stable population structure and reproductive value for populations with complex life cycles. Ecology 63: $1223-1231$

Caswell, H. (1986). Matrix models and the analysis of complex plant life. Lect. Math. Life Sci. 18: 171-233

Caswell, H., Werner, P. A. (1.978). Transient behavior and Iife history analysis of teasel (Dipsacus sylvestns Huds.). Ecology 59: 53-66

Chapman, A. R. O. (1984). Reproduction, recruitment and mortality in two species of Laminaria in southeast Nova Scotia. J. exp. mar. Biol. Ecol 78: 99-110

Chapman, A. R. O. (1986). Age versus Stage: an analysis of age and size specific mortality and reproduction in a popu- 
lation of Laminaria longicruris. J. exp. mar Biol. Ecol. 97: 113-122

De Wreede, R. E. (1984). Growth and age class distribution of Pterygophora californica (Phaeophyta). Mar Ecol. Prog. Ser 19: 93-100

De Wreede, R. E. (1986). Demographic characteristics of Pturygophora californica (Lamınariales, Phaeophyta). Phycologia 25: 11-17

Enright, 2N., Ogden, J. (1979). Applications of transitional matrix models in forest dynamics: Araucaria in Papua New Guinea and Nothofagus in New Zealand. Aust. J. Ecol. 4: 3-23

Frye, T C. (1918). The age of Pterygophora californica. Publs Puget Sound mar biol. Stn. 2: 65-71

Harper, J. L. (1977). Population biology of plants. Academic Press, New York

Hartshorn, G. S. (1975). A matrix model of tree population dynamics. In : Golley, F. B., Medina, E. (eds.) Tropical ecological systems. Springer-Verlag, New York, p. 41-51

Hsiao, S. T C., Druehl, L. D. (1973). Environmental control of gametogenesis in Laminaria saccharina. IV In situ development of gametophytes and young sporophytes. J Phycol. 9: 160-164

Hughes, T P. (1984). Population dynamics based on individual size rather than age: a general model with a coral reef example. Am. Nat. 123: 778-795

Jensen, J. B. (1974). Morphological studies in Cystoseiraceae and Sargassaceae (Phaeophyceae) with special reference to apical organization. Univ. Calif. Publs Bot. 28: 1-61

Kain, J. M. (1963). Aspects of the biology of Laminaria hyperborea II. Age, weight and length. J. mar. biol. Ass. U.K. 43 : 129-151

Kain, J. M. (1975). The biology of Laminaria hyperborea VII Reproduction of the sporophyte. J. mar biol. Ass. U.K. 55: $567-582$

Kain, J. M. (1976). The biology of Laminaria hyperborea VIII Growth on cleared areas. J. mar. biol. Ass. U.K. 56: 267-290

Kain, J. M. (1977). The biology of Laminaria hyperborea X The effect of depth on some populations. J. mar biol. Ass U.K. $57: 587-608$

Klinger, $T$ (1984). Allocation to meiospore production in annual and perennial representatives of the genus Laminaria. M. Sc. thesis, University of British Columbia, Vancouver

Klinger, T., De Wreede, R. E. (1988). Stipe rings, age, and size in populations of Laminaria setchellii Silva (Laminariales, Phaeophyta) in British Columbia, Canada. Phycologia 27: $234-240$

Law, R. (1983). A model for the dynamics of a plant population containing individuals classified by age and size. Ecology 64: $224-230$

This article was submitted to the editor
Lefkovitch, L. P. (1965). The study of population growth in organisms grouped by stages. Biometrics 21: 1-18

Leslie, P. H. (1945). On the use of matrices in certain population mathematics. Biometrika 33: 183-212

Leslie, P. H. (1948). Some further notes on the use of matrices in population mathematics. Biometrika 35: 213-245

Lewis, E. G. (1942). On the generation and growth of a population. Sankhya 6: 93-96

Lüning, K. (1980). Critical levels of light and temperature regulating the gametogenesis of three Laminaria species (Phaeophyceae). J. Phycol. 16: 1-15

Meagher, T R. (1982). The population biology of Cha maelirium luteum, a dioecious member of the lily family two sex population projections and stable population structure. Ecology 63: 1701-1711

Pederson, P. M. (1981). Phaeophyta: life histories. In: Lobban C. S., Wynne, M. J. (eds.) The biology of seaweeds. Univ of California Press, Berkeley and Los Angeles, p. 194-217

Pollard, J. H. (1966). On the use of the direct matrix product in analysing certain stochastic population models. Biometrika 53: $397-415$

Sarukhàn, J., Gadgil, M. (1974). Studies on plant demography: Ranunculus repens L., $R$. bulbosus L., and $R$. acris L. III. A mathematical model incorporating multiple modes of reproduction. J. Ecol. 62: 921-936

Schmidt, K. P., Lawlor, L. R. (1983). Growth rate projection and life history sensitivity for annual plants with a seed bank. Am. Nat. 121: 525-539

Schreiber, R. F. (1930). Untersuchungen über Parthenogenesis, Geschlechtsbestimmung und Bastardierungsvermögen bei Laminarien. Planta 12: 331-353

Solbrig, O. T., Sarandon, R., Bossert, W. (1988). A density dependent growth model of a perennial herb, Viola fimbriatula. Am. Nat. 131. 385-400

Tanner, C. E. (1981). Chlorophyta: life histories. In: Lobban, C. S., Wynne, M. J. (eds.) The biology of seaweeds. Univ. of California Press, Berkeley and Los Angeles, p. 218-247

Usher, M. B. (1966). A matrix approach to the management of renewable resources, with special reference to selection forests. J. appl. Ecol. 3: 355-367

Werner, P. A., Caswell, H. (1977). Population growth rates and age vs. stage distribution models for teasel (Dipsacus $5 y l$ vestris Huds.). Ecology 58: 1103-11.11

West, J. A., Hommersand, M. H. (1981). Rhodophyta: life histories. In: Lobban, C. S., Wynne, M. J. (eds.) The biology of seaweeds. Univ. of California Press, Berkeley and Los Angeles, p. 133-193

Woodward, I. O (1982). Modelling population growth in stage-grouped organisms: a simple extension of the Leslie model. Aust. J. Ecol. 7. 389-394

Manuscript first received: May 11, 1989

Revised version accepted: September 12, 1989 